\title{
Context Effects in Product Line Extensions: Context Is Not Destiny
}

\author{
Michaela Wänke \\ Department of Psychology \\ Universität Heidelberg \\ Herbert Bless \\ Department of Psychology \\ Universität Trier \\ Norbert Schwarz \\ Institute for Social Research \\ University of Michigan
}

\begin{abstract}
Research on brand extensions has mainly focused on the similarity between the extension and the core brand as a determinant of assimilation of the extension to the core brand. The studies reported here (a) investigate how the evaluation of an extension can be influenced by means other than actual product similarity and (b) emphasize the role of contrast effects in the evaluation of brand extensions. Two experiments illustrate that the use of brand information in evaluations of a brand extension can be influenced by superficial characteristics of the extension that are under marketers' control, such as its name. In Experiment 1, a compact car manufactured by a sports car company received a more sports-car-typical evaluation when its name reflected the continuation rather than discontinuation of previous models. Experiment 2 suggests that name discontinuation elicits contrast to previous models. This contrast effect was more pronounced for nonexperts than for experts.
\end{abstract}


The trend to launch brand or product line extensions (e.g., Bragg, 1986) stimulated research on how consumers evaluate such extensions (for reviews see, e.g., Dubé, Schmitt, \& Bridges, 1992; Shocker, Srivastava, \& Rueckert, 1994). Based on categorization theories (Barsalou, 1989; Rosch, 1978; Rosch \& Mervis, 1975; Smith \& Medin, 1981) it is generally believed that whether a positive evaluation of the core brand is transferred to the extension is a function of the similarity between core brand and extension (e.g., Aaker \& Keller, 1990; Boush \& Loken, 1991; Boush et al., 1987; Chakravarti, MacInnis, \& Nakamoto, 1990; Park, Milberg, \& Lawson, 1991). ${ }^{1}$ Given high similarity, the extension should be categorized as a brand member and assimilation to the brand evaluation should occur. Two aspects stand out in the relevant research, namely (a) the focus on similarity of features or image concepts as a determinant of the evaluation of an extension, and of the brand in turn; and (b) the focus on the emergence of assimilation effects on evaluations of the brand and of the extension.

The research reported here departs from this tradition. First, we shift the focus from similarity per se to categorization decisions. Specifically, we propose that assimilation effects emerge whenever the extension is assigned to the brand category. Although this assignment is more likely the more similar the extension is to the brand, similarity is only one of many variables that may affect categorization decisions (Schwarz \& Bless, 1992a). Importantly, categorization decisions can be influenced by marketing instruments, such as the name assigned to the extension. This possibility increases the managerial flexibility in brand policy. Second, based on recent work on contextual influences in human judgment, we explore the possibility of contrast effects as the flip side of assimilation. Holding brand (sports car company) and extension (compact car) constant, two experiments investigate the conditions under which the extension is either assimilated to or contrasted away from the brand. Experiment 1 investigates how peripheral cues under the marketers' control may affect the transfer of brand beliefs. Experiment 2 investigates contrast. In addition, Experiment 2 tests the moderating effect of consumers' expertise on the emergence of assimilation and contrast.

\section{THE DIVERSE BASES OF CATEGORIZATION DECISIONS}

Theoretically, the impact of the brand on evaluations of brand extensions can be conceived of as the impact of category membership on the evaluation of an

\footnotetext{
${ }^{1}$ Recent findings show that a positive evaluation of an extension depends neither on similarity to the core brand per se nor on the evaluation of the core brand, but on whether specific core brand beliefs promise need fulfillment regarding the extension (Broniarczyk \& Alba, 1994). This assumption, however, holds that the specific beliefs regarding the core brand are transferred to the extension without specifying the conditions under which such assimilation will take place.
} 
exemplar. Accordingly, some authors conceptualize the dynamics underlying the impact of brands on the evaluation of brand extensions, or, vice versa, the impact of extensions on the evaluation of the brand, in terms of schema-based affect (e.g., Fiske, 1982). Consistent with theories of person perception and social judgment, research on brand extensions typically assumes that successful brand extensions require a high fit between the extension and the core brand (e.g., Aaker \& Keller, 1990; Boush \& Loken, 1991; Boush et al., 1987; Park et al., 1991; for a different view see Broniarczyk \& Alba, 1994). This fit is assumed to facilitate the transfer of brand liking and the transfer of more specific brand beliefs. In general, categorizing an exemplar as a member of a superordinate category implies that properties of the category are likely to apply to the exemplar (Rothbart \& Lewis, 1988). The inclusion of these properties in the mental representation formed of the exemplar results in an assimilation of the exemplar to the brand. Conversely, properties of the exemplar become part of the mental representation of the brand, thus changing beliefs about the core brand. This latter influence has been discussed under the heading of reciprocity effects, or, assuming a negative influence, brand dilution (e.g., Loken \& Roedder John, 1993; Park, McCarthy, \& Milberg, 1993; Romeo, 1991). In short, variables that facilitate the categorization of an extension as a brand member should also facilitate the transfer of brand beliefs to the extension and the transfer of beliefs about the extension to the brand, resulting in an assimilation of the extension and the core brand. ${ }^{2}$

Consistent with these assumptions, the literature showed that assimilation is more likely for similar product categories. Similarity may be defined by different aspects, for example, physical similarity like orange and citrus guava juice (Romeo, 1991) or functional similarity (Park et al., 1991). For example, Rolex, which is known as a brand for watches high in image appeal, will be more successful with image-enhancing products than with technical products, whereas Timex, another brand known for watches, will be more successful with technical gadgets than with image-appeal products. Hence, it has typically been concluded that similarity between product and brand is the key determinant for the transfer of brand appeal.

Perceived similarity, however, has been shown to be context dependent (Tversky, 1977) and Medin and Ross (1992) suggested that "similarity may be a by-product rather than a cause of categorization" (p. 378; see also Medin, 1989). Moreover, as the preceding examples show, similarity can be defined by many different shared properties, such as product categories or image concepts, making similarity a fuzzy concept that may be ill suited as a defining condition for categorization. In light of the many difficulties related to similarity, Herr, Farquahar, and Fazio (1996) proposed the more extensive concept of relatedness as a prerequisite for assimilation of extension evaluations. Relatedness includes a much

\footnotetext{
${ }^{2}$ Whether the transfer of brand attributes to the extension is desirable and whether the transfer contributes to the success of the extension is a different question (see Broniarczyk \& Alba, 1994).
} 
wider range of variables than similarity and is not necessarily based on physical features. One may imagine that any shared variable (e.g., product function, manufacturing process, distribution channels, etc.) may serve as a basis for the perception of relatedness, which in turn may affect categorization. In addition, categorization decisions may also be triggered by other factors. Elsewhere we discuss some general variables that may affect categorization decisions (Schwarz \& Bless, 1992a), some of which may be included in the concept of relatedness, whereas others are independent of the nature of the stimuli but address external factors: category width (e.g., Schwarz \& Bless, 1992b), typicality (e.g., Kunda \& Oleson, 1997; Lambert \& Wyer, 1990), explicit categorization (Wänke, Bless, \& Schwarz, 1997), extremity (Herr, 1986; Herr, Sherman, \& Fazio, 1983), conversational norms (Schwarz, Strack, \& Mai, 1991; Strack, Schwarz, \& Wänke, 1991), or awareness of external influences (e.g., Lombardi, Higgins, \& Bargh, 1987; Strack, Schwarz, Bless, Kübler, \& Wänke, 1993). Some of these variables have also been shown to play a role in brand extensions.

For example, wide categories allow for the inclusion of a broader range of exemplars than narrow categories (e.g., every American politician is a member of the wide category "American politicians" but not a member of the more narrow category "Republican politicians") and so on. Accordingly, wide categories facilitate the emergence of assimilation effects, whereas narrow categories facilitate the emergence of contrast effects (Schwarz \& Bless, 1992b; Stapel \& Schwarz, in press; Wänke, 1996). Consistent with this reasoning, Boush and Loken (1991) observed that extending to different product categories was more successful for broad brands than for narrow brands. Similarly, the more typical or representative an exemplar is for a category, the more likely it will be included in the representation of the category. With regard to brand extensions, we would thus assume that products typical for a brand are more likely to be evaluated in line with the brand than products low in typicality. This assumption is supported by the findings of Boush and Loken (1991; see also Loken \& Roedder John, 1993, for the effect of typicality on brand evaluations).

Importantly, variables such as typicality or category width pertain to the physical or functional nature of the brand or the extension. Accordingly, they focus marketers' attention on issues of product design and brand image. We propose that this focus entails unnecessary restrictions for marketing strategies. As a growing body of research demonstrates, categorization is not necessarily driven by the characteristics of the stimuli. For example, children, money, and photo albums do not share any features that render them similar. Nevertheless, they can be assigned to the same category as Barsalou (1983) demonstrated, in this case the ad hoc category of "things to carry out of the house in the case of fire." As this example illustrates, categorizations are highly context dependent and can be based on a broad range of different criteria. Other work has already argued that the evaluation of brand extensions is not necessarily determined by physical similarity and has drawn 
attention to variables such as a common image or concept, which may also affect categorization (Herr et al., 1996; Park et al., 1991). However, independent of whether the brand and the extension were physically, imagewise, or conceptually related, the relation was predetermined by the nature of the brand and the extension. In contrast, the notion of flexible categorization suggests that marketers may draw on a broader range of manipulations to influence consumers' categorization of a given brand and extension.

Demonstrating the impact of arbitrary categorization tasks on consumer judgment, Wänke et al. (1997) presented four consumer goods (wine, lobster, cigarettes, and a TV Guide) and manipulated explicit categorization instructions. When the instructions induced participants to assign wine and lobster to the same category, they subsequently evaluated wine more favorably than when instructions induced them to assign wine and lobster to different categories. These differences in evaluations were obtained despite the fact that the same range of products was presented to all participants. The observation that categorization decisions can be driven by variables that are unrelated to the products' features has important implications for marketers. Specifically, it broadens the range of marketing strategies that may be used to facilitate the transfer of brand beliefs and it potentially frees brand policy from the restrictions imposed by given brand characteristics. Rather than seeking suitable extensions, managers may seek marketing strategies that facilitate the inclusion of a given extension into the brand.

In this article, we explore one such strategy, namely the use of product names that signal that an extension constitutes a continuation or a discontinuation of a previous product line.

\section{EXPERIMENT 1}

In a first attempt to demonstrate how marketing tools can actively influence the impact of brand beliefs on the evaluation of the extension, we focus on the relation of the name of the extension to the names of previous brand models. We assume that model names that resemble the names of previous models will suggest continuation of the product line and will thus facilitate the transfer of brand beliefs, resulting in assimilation effects. Specifically, participants evaluated a newly launched compact car, which was presented with names that either did or did not resemble the names of sports cars the brand had previously launched. One may argue that by manipulating name resemblance while keeping everything else constant, we nevertheless manipulated perceived similarity. Note, however, that such superficial similarities are easy to influence in an applied context and do not require similarity in the actual features of the product. Hence, in contrast to other available research, we varied neither the product categories used nor the central features of the extension. In fact, we presented an identical extension and an 
identical core brand and merely varied whether the model name suggested continuation or discontinuation of the product line of a sports car brand. Our expectations are summarized in Hypothesis 1.

H1: A new model will be evaluated higher on attributes relevant to the previous product line when the name of the new model suggests continuation of the previous line rather than discontinuation.

The marketing literature usually addresses the transfer of favorable brand beliefs, but, in fact, no brand or product line possesses only favorable attributes. Favorability of an attribute is, of course, not independent from the product function. What is favorable for one product is not necessarily favorable for any other product (for a similar notion see Broniarczyk \& Alba, 1994). Moreover, in most instances, products or brands are not only defined by the attributes they possess, but also by those they do not possess. For example, sports cars are typically fast, but not roomy. Thus, rather than referring to favorable or unfavorable features, a better approach would be to think of the presence and absence of attributes, both of which may be favorable or unfavorable depending on the specific product. If we define productrelevant features as the features a product typically does or does not possess, our hypotheses should be phrased more precisely:

H1a: A new model will be evaluated higher on attributes typical for the previous product line when the name of the new model suggests continuation of the previous line rather than discontinuation.

H1b: A new model will be evaluated lower on attributes atypical for the previous product line when the name of the new model suggests continuation of the previous line rather than discontinuation.

Method

Participants. Forty-nine undergraduates from the University of Illinois participated in the experiment in fulfillment of course requirements.

Procedure. Participants were recruited for an experiment on product evaluation and were told that they would read about a car by a fictitious brand and would have to evaluate it. To form an impression of the fictitious Winston brand, participants first read descriptions of the company's three recent models (see Appendix). ${ }^{3}$ These models were clearly described as sports cars (e.g., "was voted

\footnotetext{
${ }^{3}$ Although the name Winston may carry a sportive connotation due to the involvement of the cigarette brand Winston in motor sports and thus contribute to the perceived sportiveness of the fictitious car brand, this influence would be equal for all conditions.
} 
sports car of the year 1987"). The models' names were Winston Silverhawk, Winston Silverpride, and Winston Silverstar. After participants had read the three descriptions, they read a description of the company's latest model. The introduction stated that the company launched this car to enter the compact car market. Accordingly, the car was described as small but roomy and neat looking. In the continuation condition the car was named Winston Silverray, thus featuring a name that continued the previous line; in the discontinuation condition the car was introduced as the Winston Miranda. After reading the description of the target car, participants were asked to evaluate the car along several dimensions, using 9-point rating scales ranging from 1 (does not apply at all) to 9 (applies very much). Based on a pilot study, we used five dimensions that typically apply to sports cars $(M=$ 6.6 on a 7-point rating scale; sports car high: advanced technology, fast, sports car, high quality, great design) and five dimensions that typically do not apply ( $M=$ 3.4; sports car low: safe, family car, roomy, comfortable, practical).

Pilot study. To rule out the possibility that the names of the extension (Winston Silverray vs. Winston Miranda) differed with respect to sportiveness, we ran an additional pilot study. Thirty participants received descriptions of the compact car with the name assignment Winston Silverray or Winston Miranda, but were not exposed to descriptions of the previous models. Their evaluations along the previously mentioned dimensions (see following for the compound score) revealed no differential impact of the names per se $(M=-.67$ vs. -.32 for Miranda vs. Silverray, respectively), $t<1$, in the absence of a relevant product line context.

\section{Results and Discussion}

Three compound scores were computed: one by averaging the scores on the five dimensions on which sports cars in general were seen as low (Cronbach's $\alpha=.81$ ), one by averaging the five dimensions on which sports cars in general were seen as high (Cronbach's $\alpha=.86$ ), and one summary sports car score by subtracting the former from the latter (Cronbach's $\alpha=.64$, resulting in values from -8 to +8 , with higher values reflecting higher sports car typicality). As shown in Table 1, name continuation versus discontinuation produced a highly specific pattern of how the compact car was evaluated. The influences on the sports-car-typical and sports-caratypical dimension are reflected in a significant interaction between dimension (treated as a within-subject factor) and name continuation, $F(1,47)=9.94, p<.003$. This is equivalent to a main effect of name on the difference score described earlier. The specific patterns predicted by $\mathrm{H} 1 \mathrm{a}$ and $\mathrm{H} 1 \mathrm{~b}$ that comprise this interaction are also assessed. Participants tended to evaluate the compact car higher on the 
TABLE 1

Average Evaluation of the Target Car as a Function of Name Continuation

\begin{tabular}{lcc}
\hline & \multicolumn{2}{c}{ Name } \\
\cline { 2 - 3 } & Continuation $^{\mathrm{a}}$ & Discontinuation $^{\mathrm{b}}$ \\
\hline Dimensions & & \\
Typical for sports cars & 6.0 & 5.5 \\
Atypical for sports cars & 5.0 & 6.1 \\
Difference score & 1.0 & -.6 \\
\hline
\end{tabular}

Note. Each score reflects a compound measure of five ratings that were all assessed on a scale ranging from 1 to 9 . The difference score runs from -8 to +8 . Higher scores reflect a more sportscar-typical evaluation.

${ }^{\mathrm{a}} n=25$. ${ }^{\mathrm{b}} n=24$.

sports-car-typical attributes when the name suggested continuation rather than discontinuation ( $M=6.0$ vs. 5.5 ) but lower on the sports-car-atypical attributes ( $M$ $=5.0$ vs. 6.1 ). The latter contrast was significant, $F(1,47)=6.82, p<.01$, providing support for H1b, but the typical dimension difference was not significant, $F(1,47)$ $=1.28, p<.27$, failing to support H1a. Thus, continuing the name of the sports car line induced the belief that the compact car possessed fewer of the attributes atypical of a sports car, and to a lesser extent, more attributes typical for a sports car than did name discontinuation. This presumably reflects that the name continuation elicited an inclusion of the extension into the category of the previous product line, thus licensing the derivation of relevant attributes from this superordinate category. Note that these patterns emerged despite identical context and target information in each condition. The previous product line influenced the evaluation of an extension quite differently, merely as a function of whether the extension continued or discontinued the names of the previous products.

The different impact of name continuation versus discontinuation on the transfer of specific brand beliefs is of profound relevance if we frame the beliefs in terms of favorability. Note that not all attributes typical for sports cars are desirable for a compact car. For example, sports cars were rated rather unfavorably on dimensions such as roomy, comfortable, practical, and safe. These attributes are, however, rather desirable for a compact car. Discontinuing the name of the sports car line resulted in higher ratings on these attributes, which were seen as atypical for sports cars. Thus, by avoiding that a new model is included into the brand representation, marketers can detach the new model from preexisting brand beliefs that may harm its success.

Contrary to our expectations, however, the (dis)continuation of the name did not significantly affect beliefs about attributes that sports cars typically possess. Instead, it only affected beliefs about attributes that sports cars typically do not 
possess. At present, it is unclear whether this is a systematic effect or is limited to the particular materials used. One possible explanation is that some of the dimensions we selected as typical for sports cars are not necessarily atypical for compact cars (e.g., high quality, great design) and may already be represented in consumers' representations of the category of compact cars. If so, inducing consumers to derive these concepts from the previous product line would not result in the addition of any new attributes. Logically, the inclusion of an exemplar into a superordinate category can only change the evaluation of the exemplar when the superordinate category allows the derivation of new attributes (see Schwarz \& Bless, 1992a). When the attributes of the exemplar and the superordinate category are redundant, inclusion does not result in changes in the representation of the exemplar and hence does not affect evaluation. To address this redundant attributes hypothesis we conducted a separate analysis of the two sports-car-typical attributes that are least likely to be part of consumers' representation of compact cars, namely fast and sports car. Consistent with the preceding analysis, participants rated the new car marginally higher on these attributes (average score) under name continuation than under discontinuation conditions $(M \mathrm{~s}=5.8$ vs. 4.9$), F(1,47)=2.69, p<.11$. In contrast, no difference was obtained on the remaining attributes of great design, advanced technology, and high quality $(M s=6.2$ vs. 6.0 , average score), $F(1,47)$ $<1$. Obviously, more focused tests are required to assess the general value of the redundant attributes hypothesis entailed in the inclusion-exclusion model of context effects (Schwarz \& Bless, 1992a). In Experiment 2, we further investigated the dynamics underlying the evaluation of an extension when it is excluded from the representation formed of the brand.

\section{BEYOND ASSIMILATION: CONTRAST EFFECTS IN BRAND EXTENSION}

So far, we have framed our discussion entirely in terms of which conditions favor assimilation. In doing so, we remained within the framework provided by the literature on brand extension, which primarily focuses on assimilation effects and addresses the absence of assimilation effects as the alternative outcome of primary concern. This focus on the presence or absence of assimilation effects is surprising in light of empirical findings that suggest that brand extensions may also result in contrast effects. For example, Boush and Loken (1991) varied the typicality of product categories and observed rather negative evaluations for extremely atypical product categories. They concluded that "the negative attitude towards extremely unlikely or atypical products that a brand might make went beyond the failure of a positive attitude to "rub off' on the new product" (p. 25). They further acknowledged that these results are incompatible with models that assume a neutral evaluation in case of a low category fit (e.g., Fiske, 1982). In a more controlled study, Romeo 
(1991) reported an increase in brand favorability after negative information about a dissimilar extension was provided. The fact that these findings are difficult to explain on the basis of current theorizing about brand extensions reflects the lack of a comprehensive framework that conceptualizes the emergence of assimilation as well as contrast effects in this domain. Such frameworks, however, have been developed in the social judgment literature.

Social judgment research has repeatedly demonstrated that assimilation is only one possible outcome of contextual influences. In many situations, context information may also elicit contrast effects (e.g., Herr, 1986, 1989; Herr et al., 1983; Martin, 1986; Martin, Seta, \& Crelia, 1990; Schwarz \& Bless, 1992a, 1992b; Stapel, Koomen, \& van der Pligt, 1996; Strack, 1992). Most relevant to the discussion here, several models predict contrast effects when the context and target are not assigned to the same category, although the specific theoretical assumptions differ to some degree. We illustrate the general logic using the results of Experiment 1 as an example.

Having categorized the Winston compact car as a continuation of previous Winston sports cars, our participants inferred specific features that are typical for sports cars, such as fast, sportive, not practical, not roomy, and so on. However, they did not assign the new car to the sports car category when the name symbolized the discontinuation of the previous line. In this case, the previous models may be used as a standard of comparison against which the new model is evaluated (Herr, 1986; Herr et al., 1983; Schwarz \& Bless, 1992a). Herr (1986) proposed that when the feature overlap between a target and a context category is low, the context stimuli will not be categorized with the target but will be used as a standard of comparison, resulting in contrast in the target evaluation. For example, whereas moderate context stimuli, which are presumably high in feature overlap, elicit assimilation, extreme ones, for which feature overlap is lower, elicit contrast. Generalizing this assumption beyond the case of feature overlap, the inclusion-exclusion model (Schwarz \& Bless, 1992a) predicts that information that is excluded from the target category may be used as a standard of comparison, independent of the variable that drives exclusion in the first place.

Whereas these comparison-based approaches focus on changes in the representation of the standard of comparison, other process assumptions focus on changes in the representation of the target. For example, Martin's set-reset model (Martin, 1986; Martin et al., 1990) and the subtraction mechanism of the inclusion-exclusion model (Schwarz \& Bless, 1992a) assume that individuals may determine that the use of some highly accessible information in forming a representation of the target may be inappropriate. This may be the case because individuals are aware that the information came to mind for some irrelevant reason (e.g., Lombardi et al., 1987; Martin, 1986; Strack et al., 1993) or because its use would violate conversational norms (e.g., Schwarz et al., 1991). In this case, the information will be excluded from representation formed of the target, resulting in 
a representation that contains fewer positive (negative) features and accordingly elicits less positive (or less negative, respectively) judgments (e.g., Schwarz et al., 1991). Moreover, individuals may search for additional information that is distinct from the information they consider inappropriate, resulting in the subsequent use of information of a different valence (e.g., Martin, 1986; Martin et al., 1990). Both of these mechanisms result in a shift of the evaluation away from the implications of the contextual information (i.e., a contrast effect).

In sum, various theoretical conceptualizations would predict the emergence of contrast effects rather than the mere absence of assimilation effects on evaluations of a brand extension if consumers fail to categorize the extension as a member of the brand. ${ }^{4}$ Clearly, this should be alarming to brand managers because an attempt to achieve brand categorization may actually do more harm than good in the case of failure. This is particularly relevant, because Experiment 1 demonstrated that categorization decisions are not necessarily predetermined by product-inherent features but may be influenced by rather subtle cues, suggesting that it may not take much for assimilation effects to reverse into contrast effects. Hence, the line between a successful and a disastrous marketing strategy may be rather thin and the determining factors may not, at present, be well understood.

\section{EXPERIMENT 2}

The results of Experiment 1 clearly demonstrate a differential impact of the product line on the evaluation of the extension as a function of name continuation. However, for the discussion here, it is unclear whether the lower ratings for sports-car-typical attributes and the higher ratings for sports-car-atypical attributes obtained under discontinuation conditions reflect a contrast effect, merely the absence of the assimilation effect obtained under continuation conditions, or both. Experiment 2 addresses this issue by including a control condition, in which the target car is evaluated independent of the experimental context.

H2: Compared to a no-context control group, a new model will be evaluated higher on attributes typical for the brand image when the name suggests continuation of the previous product line (inclusion).

\footnotetext{
${ }^{4}$ In addition, correction models also assume that individuals may become aware that it is inappropriate to use a particular piece of information. These models, however, do not assume that this results in a change in the mental representation of the target. Instead, they locate the effect at the output stage and assume that individuals correct for the presumed influence, often resulting in overcorrection (e.g., Strack, 1992; Wegener \& Petty, 1995; Wilson \& Brekke, 1994). With regard to this discussion, however, there is no theoretical reason to assume that name discontinuation would trigger correction.
} 
H3: Compared to a no-context control group, a new model will be evaluated lower on attributes typical for the brand image when the name suggests discontinuation of the previous product line (exclusion).

These hypotheses are of considerable applied relevance and the present design allows us to determine the role of categorization decisions in the emergence of assimilation and contrast effects in brand extensions. This design, however, does not allow us to determine whether any obtained contrast effect is due to changes in the representation of the target, changes in the representation of the standard, or corrections at the output stage. This differentiation awaits further research once the emergence of contrast effects as a function of categorization decisions has been established in this domain.

\section{The Role of Consumer Expertise}

In addition, we would like to introduce a further variable of theoretical interest, namely consumers' expertise. A rich literature on expertise in consumer research generally predicts that nonexperts are more prone to be influenced by contextual variables than experts (e.g., Bettman \& Sujan, 1987; Bickart, 1992; Hutchinson, 1983; Rao \& Monroe, 1988; however, see Herr, 1989, for opposite results, and Lynch, Chakravarti, \& Mitra, 1991, for a discussion). It is often assumed that experts are more confident in their judgments and thus less susceptible to contextual cues. Drawing on differences in the amount of chronically accessible information and different cognitive processes, we would also predict smaller context effects for experts than for nonexperts. Compared to nonexperts, experts characteristically possess a rich and well-organized knowledge structure in the specific domain (see Alba \& Hutchinson, 1987). Because they have a relatively large amount of relevant information chronically accessible, the impact of additional information that is rendered temporarily accessible by the immediate context should be relatively weak. This reflects that the impact of a given piece of information decreases with the amount and extremity of other information used in forming a representation of the target (see Schwarz \& Bless, 1992a, for more detail). For nonexperts, on the other hand, only a small amount of information is chronically accessible. Accordingly, the representation that they form of the target is likely to be dominated by the temporarily accessible information, resulting in pronounced context effects. Based on these assumed differences in the amount of chronically accessible information, we predict that the size of context effects decreases as consumers' knowledge about the product category increases.

H4: Assimilation and contrast effects are less pronounced for experts than for nonexperts with regard to the relevant product category. 
This hypothesis clearly contradicts findings reported by Muthukrishnan and Weitz (1991), who observed more pronounced assimilation effects in evaluations of an extension and the brand for experts than for novices. They argued that experts excel over nonexperts in their ability to detect a relation between the core brand and the extension. For example, experts may be able to detect commonalities in technology that are not obvious to nonexperts. We agree that knowledge differences may result in different categorizations but propose that given a specific categorization, its impact is more pronounced for novices than for experts.

In addition to including a no-context control group and consumers' expertise as an additional factor, we introduced several other changes to improve the design of Experiment 1. First, in Experiment 1 we had presented a sports car brand and assessed the evaluation of the target product on dimensions typical for a sports car in general. To investigate more specific brand influences, Experiment 2 assessed the evaluation of the target car on dimensions that other participants had judged as typical for the specific brand Winston, rather than for sports cars in general, as was the case in Experiment 1.

Second, we used a different set of dimensions to further increase generalizability. In Experiment 1, the target car was rated along rather concrete dimensions used to describe a car (e.g., practical, roomy). Although the results of Experiment 1 show that the continuation or discontinuation of the name influenced consumers' expectations along those dimensions, in reality these expectations are prone to an easy reality check and may not last particularly long. In contrast, image-related evaluations are more abstract, less constrained by reality, and hence more enduring than the evaluations assessed in the previous experiment. To tap image-relevant features, we chose dimensions more adequate for image research (e.g., strong, active, young, etc.) in Experiment 2.

Third, in Experiment 1 the continuation versus discontinuation of the names of previous models was manipulated by changing the name of the new model. Although the pilot study had revealed no evidence that the names Silverray and Miranda may convey different images of sportiveness, the name of the target car was held constant in Experiment 2. Instead, the names of the cars that represented the previous product line were varied to provide a mirror image operationalization of the previously used manipulation of continuation and discontinuation.

\section{Method}

Sixty-four students from the University of Mannheim, Germany, participated in a 3 (continuation vs. discontinuation vs. control) $\times 2$ (experts vs. nonexperts) factorial design. All factors were varied among participants. The descriptions of the cars were similar to Experiment 1, with a few adaptations for the German setting. ${ }^{5}$

\footnotetext{
${ }^{5}$ Note that in the German context a potential influence of familiarity with the cigarette brand Winston, which may have occurred in the U.S. context, was unlikely.
} 
The procedure was the same as in Experiment 1, except that a control group was added, members of which read only the information about the new model and evaluated it without a brand context. Moreover, the name of the new model was held constant but continuation versus discontinuation was manipulated by the names of the context cars. The target car was called Winston Milano in all conditions. The three context cars were called Winston Firenze, Winston Roma, and Winston Siena in the continuation condition, giving all four cars the names of Italian cities. In the discontinuation condition the names of the three context cars were Winston Circle, Winston Square, and Winston Triangle, thus naming the previous line uniformly after geometrical figures, rendering the name of the new model distinctly different. Participants assigned to the control condition were not exposed to descriptions of any context cars.

Participants rated the target car on nine bipolar dimensions, identified in a pilot study (described later), along scales ranging from -5 to +5 . Subsequently, all participants reported their interest in cars and how much they considered themselves informed about cars on two scales ranging from 1 (not at all interested and not at all informed, respectively) to 9 (very much interested and highly informed, respectively).

Pilot Study 1. To determine the relevant dimensions for evaluation, participants of a pilot study read descriptions of the three Winston sports cars and rated the brand Winston along several bipolar dimensions. Those dimensions on which the brand Winston was rated on average more than 2 scale points above or below the midpoint on an 11-point rating scale were selected as dependent variables. The selected dimensions were: active-passive, strong-weak, modern-old-fashioned, progressive-conservative, chic-pedestrian, dynamic-static, lively-lethargic, fast-slow, and young-old. ${ }^{6}$ On all dimensions the brand scored on the positive side of the scale, indicated by the first mentioned adjective in each pair. This reflects the young and active image of the brand.

Pilot Study 2. Although we kept the name of the extension constant, it seemed necessary to ensure that the variation in the names of the previous models did not evoke different brand beliefs. Following the procedures of Pilot Study 1, 20 participants evaluated the brand Winston after being presented with sports cars named after Italian cities or after geometrical forms. The evaluations did not differ on a compound score of the dimensions identified as typical of Winston in Pilot

\footnotetext{
${ }^{6}$ The literal translation may not reflect the appropriate connotations in German: aktiv-passiv, stark-schwach, modern-altmodisch, fortschrittlich-konservativ, flott-spießig, dynamisch-statisch, lebendig-lethargisch, schnell-langsam, and jung-alt.
} 
Study $1, t<1$, indicating that the names did not contribute to the impression formed of the brand.

Pilot Study 3. In our main study, we used self-report measures to assess expertise. Because subjective expertise may often be a poor predictor of objective knowledge (Park, Mothersbaugh, \& Feick, 1994), we conducted an independent study, involving 17 participants of the same population as in the main study, to assess the validity of our measure. We found that the compound of self-reported interest and self-reported informedness correlated significantly with correct answers to objective knowledge questions, such as identifying car models in pictures $(r=.60, p<.01)$ or number of correctly listed car magazines $(r=.70, p<.001)$.

\section{Results and Discussion}

An average score of participants' reported expertise and interest in cars was computed $(r=.77)$, simply referred to as expertise. Expertise was not dependent on categorization conditions, $F(2,61)=1.13, p<.33$, and participants were grouped as experts or nonexperts according to the median split on this score $(M d n=3.00)$.

The scores of each of the nine dimensions were averaged into a compound score (Cronbach's $\alpha=.83$ ), with -5 reflecting an "old" image and +5 reflecting the "young" and "modern" image the brand as a whole had shown in the pilot study. These scores, shown in Table 2, were submitted to a 3 (continuation vs. control vs. discontinuation) $\times 2$ (high vs. low expertise) factorial analysis of variance.

As predicted, nonexperts' evaluations of the target car were significantly affected by the context manipulations, $F(2,58)=4.68, p<.02$, for the simple main effect. Participants evaluated the target car as more in line with the trendy brand image when the name suggested continuation (inclusion) and as least trendy when

TABLE 2

Average Evaluation of the Target Car as a Function of Name Continuation and Participants' Expertise

\begin{tabular}{llll}
\hline & \multicolumn{3}{c}{ Name } \\
\cline { 2 - 4 } Expertise & Continuation & Control & Discontinuation \\
\hline Nonexperts & $2.8_{\mathrm{a}}(n=12)$ & $2.5_{\mathrm{a}}(n=8)$ & $1.2_{\mathrm{b}}(n=13)$ \\
Experts & $1.6_{\mathrm{a}}(n=9)$ & $1.9_{\mathrm{a}}(n=13)$ & $2.2_{\mathrm{a}, \mathrm{b}}(n=9)$ \\
\hline
\end{tabular}

Note. The scores reflect a compound measure of nine ratings that were all assessed on a scale ranging from -5 to +5 . Higher scores reflect a more active, younger, and so on evaluation. Means with different subscripts differ significantly at $p<.05$. 
the name suggested discontinuation (exclusion), with the control group falling in between. Planned contrasts revealed that the discontinuation condition differed significantly from the continuation, $t(58)=2.88, p<.006$, and control conditions, $t(58)=-2.16, p<.04$. However, the difference between the continuation and control conditions was nonsignificant, $t<1$. Thus, a significant contrast effect emerged under discontinuation conditions, as predicted by Hypothesis 2 . Yet, the assimilation effect under continuation conditions predicted by Hypothesis 3 failed to reach significance relative to the control group.

In contrast to nonexperts, experts' evaluations were not influenced by the continuation manipulation, $F(2,58)<1$ for the simple main effect (and $t<1$ for all simple contrasts), as predicted by Hypothesis 4 . Overall, this pattern of findings is reflected in a significant interaction of context and expertise, $F(2,58)=3.50, p<$ .04 . Neither categorization, $F(2,58)=1.59, p<.22$, nor expertise, $F(1,58)<1$, showed a significant main effect.

Next, we turn to a more detailed consideration of the differences between experts and nonexperts. First, both groups did not differ in their evaluation of the Winston Milano, $t<1$, when they provided their evaluation without a context manipulation (control condition). Second, when the previous product line was introduced, nonexperts tended to evaluate the Winston Milano more in line with the trendy Winston image (i.e., young, dynamic, etc.) than experts under name continuation conditions, $t(58)=-1.87, p<.07$, and less in line with this image under name discontinuation conditions, $t(58)=1.74, p<.09$. Note, however, that these differences derive solely from the fact that the context manipulations affected the judgments of nonexperts, but not of experts. In fact, the theoretical rationale only entails predictions about the differential size of context effects and does not allow for predictions of other differences between the judgments of experts and nonexperts in the absence of specific knowledge about the representations that these groups draw on. Depending on the knowledge they bring to the task, experts may, for example, have higher comparison standards, or perhaps more realistically low standards, and hence may evaluate the car more or less favorably than nonexperts in all conditions. Independent of such differences, however, the impact of categorization manipulations should be less pronounced for experts because a large amount of chronically accessible information attenuates the impact of temporarily accessible information (see Sudman, Bradburn, \& Schwarz, 1996, pp. 103-105, for a more detailed discussion).

\section{GENERAL DISCUSSION}

Previous research on brand extensions has manipulated either relevant features of the core brand or relevant features of the extension, resulting in different degrees of similarity between extensions and brands. In contrast to these studies, we held all features of the previous product line and all features of the extension constant 
and introduced a name continuation-discontinuation manipulation to influence the use of contextual information.

As predicted, we observed that the impact of identical information about the previous product line differed as a function of the superficial characteristic of name (dis)continuation: When the name was discontinued, the extension was evaluated as less sports-car-typical or brand-typical ${ }^{7}$ than under conditions where the name was continued (Experiments 1 and 2), or where participants were not exposed to the relevant brand information to begin with (Experiment 2). The latter finding presumably indicates that the brand information was used in forming a standard of comparison, against which the extension was contrasted.

Earlier we had mentioned subtraction or reset (Martin, 1986; Schwarz \& Bless, 1992a) and correction (e.g., Strack et al., 1993) as alternative processes driving the emergence of contrast effects. Although the studies here were not designed to differentiate between these competing models, it is unlikely that the obtained results are due to either of these alternative accounts. First, subtraction and reset processes can only elicit contrast effects relative to a control group when the brand information that is subtracted from the representation under the exclusion condition is part of this representation in the control condition. For this experiment, we would need to assume that control group participants spontaneously conceptualized the fictitious brand as a typical sports car brand in the absence of any product or brand information, rendering this account implausible. Second, correction processes are based on participants' subjective theories about a likely contextual influence (see Petty \& Wegener, 1993; Stapel, Martin, \& Schwarz, in press; Strack \& Hannover, 1996). This results in contrast when participants (a) perceive a likely influence, (b) assume that this influence is assimilative in nature, and (c) overcorrect for the expected assimilation effect by adjusting their judgment in the opposite direction. To account for the findings reported here, we would therefore need to make the rather implausible assumption that participants held a subjective theory that specifies that name discontinuation results in assimilation effects, or else any corrections would not take the form of contrast. In sum, these alternative mechanisms are unlikely to account for the findings reported here.

Contrary to predictions, the assimilation of the extension to the brand under name continuation conditions failed to reach significance relative to the no-context control group in Experiment 2. In contrast, the theoretically more interesting difference between the continuation and discontinuation condition bore out clearly. Whether the unmanipulated control condition is closer to the inclusion or the exclusion condition is a function of variables that are not fully under experimental control, such as participants' chronic beliefs about cars in general. Note that in the

\footnotetext{
${ }^{7}$ To be precise, we did not measure typicality but use the term as an abbreviation for the compound score of attributes that were typical and attributes that were atypical.
} 
two experimental conditions all temporarily accessible information was identical with the exception of the name, symbolizing continuation or discontinuation. The differential findings obtained under these conditions indicate that variables other than actual feature (or image) similarity can influence the use of contextual information and the resulting context effects.

Importantly, independent studies revealed no impact of the names per se, suggesting that it is indeed the differential use of context information elicited by the continuation versus discontinuation manipulation that is responsible for the observed effects, rather than any information conveyed by the different names used. In the following sections, we address the implications for brand extensions before we turn to a discussion of consumers' expertise.

\section{Categorization Effects on Brand Extensions}

Previous research presented evidence that successful brand extensions require a high match between the original brand and the extension in terms of actual product similarity (e.g., Aaker \& Keller, 1990; Boush et al., 1987; Chakravarti, MacInnis, \& Nakamoto, 1989) or image similarity (Park et al., 1991). Only given a high fit would consumers accept the new product as an extension and readily transfer whatever beliefs they hold about the brand. Although we agree that feature or image similarity increases the likelihood of assimilation, we emphasize that similarity per se is not the cause of assimilation to context information. Rather, we propose that the specific impact that context information exerts depends on how the context information is used; that is, whether it is included in or excluded from the representation formed of the target. From this perspective, similarity is only one of many variables that influence categorization, and categorization, not similarity per se, is the crucial determinant of the emergence and direction of context effects (Schwarz \& Bless, 1992a). Accordingly, the impact of similarity can be overridden by other variables that influence categorization, as the preceding findings illustrate.

These considerations have important implications for marketers because they suggest that a high or low transfer of brand beliefs is not necessarily predetermined by the similarity of the new product and the core brand on central features. Instead, the transfer can to some extent be influenced by manipulations of superficial characteristics that influence the use of context information. In this regard, we point to the wide array of potential tools marketers can use to affect consumers' perception of a product, of which product name is just one. Product display, communication strategies, packaging, and many other variables can either individually or in combination be applied to elicit a brand categorization.

Given that the brand image is often the strongest asset of a product (Leuthesser, 1988), marketers hope that consumers will transfer (positive) beliefs associated with the familiar brand to the new launch, reflecting a within-category assimilation effect. The findings presented here render two aspects particularly important with 
respect to this strategy. First, previous research postulated as the worst outcome a lack of transfer effects, for example, in the case of a poorly matched extension. Making things worse, this research suggests that contrast effects may also be obtained, resulting in a negative impact of a positive brand. Hence, an unfortunate brand or product line extension may not only fail to elicit the desired transfer of brand beliefs, but may actually backfire by causing more negative evaluations. Marketing strategies should thus be planned very carefully as they may cause more harm than good.

Second, contrast effects may not always come undesired, which poses another, equally relevant, reason to take a closer look at the processes that may lead to contrast effects in judging extensions. There are cases in which a transfer of existing brand beliefs may be counterproductive to the marketer's goal (e.g., if a different group of consumers is targeted). The associations consumers have of an existing brand may interfere with any marketing tools to create a different image for the new product. Often this will call for the making of a new brand not associated with the unsuitable one. However, the costs involved in creating a new brand are often prohibitive. We suggest that making the best of an existing brand or product line image can also imply a strategy that tries to elicit contrast of the new product to the previous products, thus facilitating the development of a different product image. A strategy that elicits contrast may be more easily implemented than new branding and, all else being equal, may be more effective. Experiment 1 showed that contrast effects on unfavorable characteristics typical for sports cars actually may be quite desirable for compact cars. Keeping the brand name and using it for contrast purposes is especially recommended when certain aspects of the brand image should be kept but others should be changed. Thus, assimilation and contrast mechanisms can serve as positioning tools in marketing.

\section{The Impact of Expertise}

Experiment 2 also demonstrated that experts are less susceptible to context effects than nonexperts. In general, a decreased impact of contextual variables on the judgments reported by experts may reflect two different processes. As a first possibility, experts may occasionally be able to retrieve a previously formed judgment from memory, thus obliterating the need to form a judgment in the context given (see Schwarz \& Strack, 1991; Strack \& Martin, 1987). As a result, their judgment is unaffected by the present context. Note, however, that this assumption cannot account for the expertise effects in Experiment 2, as the judgments pertained to a new and fictitious product, for which no previous judgment could have been available in memory. In most cases, expertise effects are likely to reflect a second possibility, namely a differential amount of chronically accessible information about the respective content domain. According to the inclusion-exclusion model, the impact of a given piece of information rendered accessible by the context decreases 
as the amount and extremity of other information included in the representation increases (see Schwarz \& Bless, 1992a, for a more detailed discussion).

In Experiment 2, participants who reported having more knowledge about cars were not affected by either the name continuation or name discontinuation manipulation. We assume that this reflects that the experts could draw on a larger amount of chronically accessible information about cars in constructing representations of the target and a standard, thus diluting the impact of the temporarily accessible contextual information. We agree, however, that expertise in a product category may also trigger other effects. For example, based on their knowledge experts may draw different inferences from a piece of information than nonexperts (e.g., Muthukrishnan \& Weitz, 1991). Hence, whether experts are more or less influenced than nonexperts depends on the relevance of the specific inference drawn. However, independent of this, any specific piece of information that is made accessible will have a more pronounced effect on nonexperts compared to experts, reflecting the differential amount of chronically accessible information.

\section{CONCLUSIONS}

In summary, the experiments reported here illustrate that the same information about a brand and a brand extension can result in different evaluations of the extension, depending on superficial characteristics that influence the use of context information. Moreover, our findings draw attention to the emergence of contrast effects in the evaluation of brand extensions, reflecting the use of brand information as a standard of comparison. Hence, the worst outcome of a failed brand extension is not the mere absence of a transfer of brand beliefs, but a backfire effect by which a positive brand not only fails to help the extension, but actually hurts it. The underlying cognitive processes can be conceptualized in terms of general judgment models that predict the emergence of assimilation and contrast effects.

A better understanding of these processes will enable marketers to employ them to their advantage, as these experiments illustrate: Although marketers can hardly manipulate the context determined by the brand or product line, or the key features of the new product, they may often be able to manipulate how consumers use the contextual information, as illustrated by the impact of our name continuation-discontinuation manipulation.

\section{ACKNOWLEDGMENTS}

This research was supported by Grant $\mathrm{Bl} 289 / 5-1$ from the Deutsche Forschungsgemeinschaft to the authors, Grant SWF 0044-6 from the BMFT to Norbert Schwarz, and a fellowship from the DAAD to Michaela Wänke. 


\section{REFERENCES}

Aaker, D., \& Keller, K. (1990). Consumer evaluations of brand extensions. Journal of Marketing, 54, $27-41$.

Alba, J., \& Hutchinson, J. (1987). Dimensions of consumer expertise. Journal of Consumer Research, 13, 411-454.

Barsalou, L. W. (1983). Ad hoc categories. Memory and Cognition, 11, 211-217.

Barsalou, L. W. (1989). Intraconcept similarity and its implications for interconcept similarity. In S. Vosniadou \& A. Ortony (Eds.), Similarity and analogical reasoning (pp. 76-121). Cambridge, England: Cambridge University Press.

Bettman, J., \& Sujan, M. (1987). Effects of framing on evaluation of comparable and non-comparable alternatives by expert and novice consumers. Journal of Consumer Research, 14, 141-154.

Bickart, B. (1992). Question-order effects and brand evaluations: The moderating role of consumer knowledge. In N. Schwarz \& S. Sudman (Eds.), Context effects in social and psychological research (pp. 63-80). New York: Springer-Verlag.

Boush, D., \& Loken, B. (1991). A process tracing study of brand extension evaluations. Journal of Marketing Research, 19, 16-28.

Boush, D., Shipp, S., Loken, B., Gencturk, E., Crockett, S., Kennedy, E., Michall, B., Misurell, D., Rochford, L., \& Strobel, J. (1987). Affect generalization to similar and dissimilar brand extensions. Psychology and Marketing, 4, 225-237.

Bragg, A. (1986, November). Back to the future. Sales and Marketing Management, 137, 61-62.

Broniarczyk, S. M., \& Alba, J. W. (1994). The importance of the brand in brand extension. Journal of Marketing Research, 3, 214-228.

Chakravarti, D., MacInnis, D., \& Nakamoto, K. (1990). Product category perception, elaborative processing and brand name extension strategies. Advances in Consumer Research, 17, 910-916.

Dubé, L., Schmitt, B. H., \& Bridges, S. (1992). Categorization research and brand extensions. Advances in Consumer Research, 19, 255-259.

Fiske, S. (1982). Schema-triggered affect: Applications to social perception. In M. S. Clark \& S. T. Fiske (Eds.), Affect and cognition: The 17th annual Carnegie Symposium on Cognition (pp. 171-190). Hillsdale, NJ: Lawrence Erlbaum Associates, Inc.

Herr, P. M. (1986). Consequences of priming: Judgment and behavior. Journal of Personality and Social Psychology, 51, 1106-1115.

Herr, P. M. (1989). Priming price: Prior knowledge and context effects. Journal of Consumer Research, $16,67-75$.

Herr, P. M., Farquahar, P. H., \& Fazio, R. H. (1996). Impact of dominance and relatedness on brand extensions. Journal of Consumer Psychology, 5, 135-160.

Herr, P. M., Sherman, S. J., \& Fazio, R. H. (1983). On the consequences of priming: Assimilation and contrast effects. Journal of Experimental Social Psychology, 19, 323-340.

Hutchinson, J. (1983). On the locus of range effects in judgment and choice. In R. Bagozzi \& A. Tybout (Eds.), Advances in consumer research (Vol. 10, pp. 305-308). Ann Arbor, MI: Association for Consumer Research.

Kunda, Z., \& Oleson, K. C. (1997). When exceptions prove the rule: How extremity of deviance determines the impact of deviant examples on stereotypes. Journal of Personality and Social Psychology, 72, 965-979.

Lambert, A. J., \& Wyer, R. S. (1990). Stereotypes and social judgment: The effects of typicality and group heterogeneity. Journal of Personality and Social Psychology, 59, 676-691.

Leuthesser, L. (Ed.). (1988). Defining, measuring and managing brand equity: A conference summary (Rep. No. 88-104). Cambridge, MA: Marketing Science Institute.

Loken, B., \& Roedder John, D. (1993). Diluting brand beliefs: When do brand extensions have a negative impact? Journal of Marketing, 57, 71-84. 
Lombardi, W., Higgins, E., \& Bargh, J. (1987). The role of consciousness in priming effects on categorization: Assimilation and contrast as a function of awareness of the priming task. Personality and Social Psychology Bulletin, 13, 411-429.

Lynch, J., Chakravarti, D., \& Mitra, A. (1991). Contrast effects in consumer judgments: Changes in mental representations or anchoring of rating scales? Journal of Consumer Research, 18, 284-297.

Martin, L. L. (1986). Set/reset: Use and disuse of concepts in impression formation. Journal of Personality and Social Psychology, 51, 493-504.

Martin, L. L., Seta, J. J., \& Crelia, R. A. (1990). Assimilation and contrast as a function of people's willingness to expend effort in forming an impression. Journal of Personality and Social Psychology, 59, 27-37.

Medin, D. L. (1989). Concepts and conceptual structure. American Psychologist, 44, 1469-1481.

Medin, D. L., \& Ross, R. H. (1992). Cognitive psychology. Fort Worth, TX: Harcourt Brace Jovanovich.

Muthukrishnan, A. V., \& Weitz, B. A. (1991). Role of product knowledge in evaluation of brand extension. Advances in Consumer Research, 18, 407-413.

Park, C. W., McCarthy, M. S., \& Milberg, S. J. (1993). The effects associated with direct and associative brand extension strategies on consumer response to brand extensions. Advances in Consumer Research, 20, 28-33.

Park, C. W., Milberg, S., \& Lawson, R. (1991). Evaluation of brand extensions: The role of product feature similarity and brand concept consistency. Journal of Consumer Research, 18, 185-193.

Park, C. W., Mothersbaugh, D. L., \& Feick, L. (1994). Consumer knowledge assessment. Journal of Consumer Research, 2I, 71-82.

Petty, R. E., \& Wegener, D. T. (1993). Flexible correction processes in social judgment: Correcting for context-induced contrast. Journal of Experimental Social Psychology, 29, 137-165.

Rao, A., \& Monroe, K. (1988). The moderating effect of prior knowledge on cue utilization in product evaluations. Journal of Consumer Research, 15, 253-264.

Romeo, J. (1991). The effect of negative information on the evaluation of brand extensions and the family brand. Advances in Consumer Research, 17, 399-406.

Rosch, E. H. (1978). Principles of categorization. In E. Rosch \& B. B. Lloyd (Eds.), Cognition and categorization. Hillsdale, NJ: Lawrence Erlbaum Associates, Inc.

Rosch, E. H., \& Mervis, C. (1975). Family resemblances: Studies in the internal structures of categories. Cognitive Psychology, 7, 573-605.

Rothbart, M., \& Lewis, S. (1988). Inferring category attributes from exemplar attributes: Geometric shapes and social categories. Journal of Personality and Social Psychology, 55, 861-872.

Schwarz, N., \& Bless, H. (1992a). Constructing reality and its alternatives: Assimilation and contrast effects in social judgment. In L. L. Martin \& A. Tesser (Eds.), The construction of social judgment (pp. 217-245). Hillsdale, NJ: Lawrence Erlbaum Associates, Inc.

Schwarz, N., \& Bless, H. (1992b). Scandals and the public's trust in politicians: Assimilation and contrast effects. Personality and Social Psychology Bulletin, 18, 574-579.

Schwarz, N., \& Strack, F. (1991). Context effects in attitude surveys: Applying cognitive theory to social research. In W. Stroebe \& M. Hewstone (Eds.), European review of social psychology (Vol. 2, pp. 31-50). Chichester, England: Wiley.

Schwarz, N., Strack, F., \& Mai, H.-P. (1991). Assimilation and contrast effects in part-whole question sequences: A conversational logic analysis. Public Opinion Quarterly, 55, 3-23.

Shocker, A. D., Srivastava, R. K., \& Rueckert, R. W. (1994). Challenges and opportunities facing brand management: An introduction to the special issue. Journal of Marketing Research, 31, 149-158.

Smith, E. E., \& Medin, D. L. (1981). Categories and concepts. Cambridge, MA: Harvard University Press.

Stapel, D. A., Koomen, W., \& van der Pligt, J. (1996). The referents of trait inferences: The impact of trait concepts versus actor-trait links on subsequent judgments. Journal of Personality and Social Psychology, 70, 437-450. 
Stapel, D. A., Martin, L. L., \& Schwarz, N. (in press). The smell of judgments: What instigates correction processes in social judgment? Personality and Social Psychology Bulletin.

Stapel, D. A., \& Schwarz, N. (in press). The Republican who did not want to become president: An inclusion/exclusion analysis of Colin Powell's impact on evaluations of the Republican Party and Bob Dole, Personality and Social Psychology Bulletin.

Strack, F. (1992). The different routes to social judgments: Experiential versus informational strategies. In L. L. Martin \& A. Tesser (Eds.), The construction of social judgment (pp. 249-275). Hillsdale, NJ: Lawrence Eribaum Associates, Inc.

Strack, F., \& Hannover, B. (1996). Awareness of influence as a precondition for implementing correctional goals. In P. Gollwitzer \& J. Bargh (Eds.), The psychology of action (pp. 579-596). New York: Guilford.

Strack, F., \& Martin, L. (1987). Thinking, judging, and communicating: A process account of context effects in attitude surveys. In H. J. Hippler, N. Schwarz, \& S. Sudman (Eds.), Social information processing and survey methodology (pp. 123-148). New York: Springer-Verlag.

Strack, F., Schwarz, N., Bless, H., Kübler, A., \& Wänke, M. (1993). Awareness of the influence as a determinant of assimilation versus contrast. European Journal of Social Psychology, 23, 53-62.

Strack, F., Schwarz, N., \& Wänke, M. (1991). Semantic and pragmatic aspects of context effects in social and psychological research. Social Cognition, 9, 111-125.

Sudman, S., Bradburn, N., \& Schwarz, N. (1996). Thinking about answers: The application of cognitive processes to survey methodology. San Francisco: Jossey-Bass.

Tversky, A. (1977). Features of similarity. Psychological Review, 84, 327-353.

Wänke, M. (1996). Informationsnutzung bei der Konstruktion von Einstellungsurteilen: Schnittstellen von Sozialpsychologie und Konsumentenpsychologie [Information use in the construal of attitude judgments: Crossroads between social psychology and consumer psychology]. Habilitationthesis, Universität Heidelberg, Heidelberg, Germany.

Wänke, M., Bless, H., \& Schwarz, N. (1997). Contrast or assimilation? The influence of explicit categorization. Manuscript under review.

Wegener, D. T., \& Petty, R. E. (1995). Flexible correction processes in social judgment: The role of naive theories in corrections for perceived bias. Journal of Personality and Social Psychology, 68, 36-51.

Wilson, T. D., \& Brekke, N. (1994). Mental contamination and mental correction: Unwanted influences on judgments and evaluations. Psychological Bulletin, 116, 117-142.

Accepted by Paul Herr.

\section{APPENDIX}

The following are the stimulus materials for Experiment 1, which was run in the United States. The materials for Experiment 2 are highly similar but in German.

\section{Winston SILVERSTAR}

The Winston SILVERSTAR was the "Sports car of the year 1986." With the SILVERSTAR, Winston had built a classic sports car in design and technology: The aerodynamic design housed a powerful 24-valve twin dual-cam engine and 220 horsepower for speed and power. Rally-tuned sport suspension made the SILVERSTAR agile in quick direction changes. Aluminum alloy wheels helped 
the SILVERSTAR stay on the ground. Inside, the SILVERSTAR was a typical two-seater with low pilot seats, a futuristic instrument panel, and a small sportive steering wheel. Outside, it looked sleek and perfect.

\section{Winston SILVERHAWK}

In 1987, Winston launched the SILVERHAWK, a more economical version of the Silverstar. The SILVERHAWK kept the aerodynamic exterior with its spoiler but featured a less lavish interior and most of all reduced engine power. However the 16-valve twin-cam engine is still powerful enough for quick starts and sportive driving. To make the SILVERHAWK more versatile the company added narrow rear seats and a small trunk. Technology-wise, the engineers improved the fuel-injection system. The SILVERHAWK is smaller, more practical, and not quite as fast and powerful as the Silverstar. The SILVERHAWK was made for people who drive for fun and want a technologically advanced car, but do not want to spend a lot on it.

\section{Winston SILVERPRIDE}

In 1989, after the success of the Silverstar and the Silverhawk, Winston introduced the SILVERPRIDE. The SILVERPRIDE was another breakthrough in affordable sports cars. The SILVERPRIDE incorporated the newest technology and was an overall improvement in automotive state of the art. Its design won high acclaim as the best looking car in its class. A new combustion system increased performance and efficiency. The SILVERPRIDE was leading the field in installing four-speaker stereo systems as standard equipment. With all these things combined, the SILVERPRIDE offered an exciting, fast, and fun ride.

Having had so much success in the sports car market with the SILVERSTAR, the SILVERHAWK, and the SILVERPRIDE, Winston expanded its business to a new market. In 1991 Winston built a new model for the compact car market.

\section{Winston SILVERRAY/MIRANDA}

Its modern shape makes the SILVERRAY/MIRANDA extremely fuel efficient. Although the SILVERRAY/MIRANDA looks small with its only two doors, the interior is surprisingly roomy. Maximizing interior room without losing handiness and agility guided the designing of the SILVERRAY/MIRANDA. A large trunk completes that impression. In addition, the amazingly comfortable rear seats fold back for even more loading space. An electronic transmission system, antilock brakes, and improved fuel injection guarantee a high standard in driving performance. 